\title{
Quantification of Propagules of the Laurel Wilt Fungus and Other Mycangial Fungi from the Redbay Ambrosia Beetle, Xyleborus glabratus
}

\author{
T. C. Harrington and S. W. Fraedrich
}

First author: Department of Plant Pathology, Iowa State University, Ames 50011; and second author: Southern Research Station, United States Department of Agriculture Forest Service Athens, GA 30605. Accepted for publication 16 June 2010.

ABSTRACT

\begin{abstract}
Harrington, T. C., and Fraedrich, S. W. 2010. Quantification of propagules of the laurel wilt fungus and other mycangial fungi from the redbay ambrosia beetle, Xyleborus glabratus. Phytopathology 100:11181123 .

The laurel wilt pathogen, Raffaelea lauricola, is a fungal symbiont of the redbay ambrosia beetle, Xyleborus glabratus, which is native to Asia and was believed to have brought $R$. lauricola with it to the southeastern United States. Individual $X$. glabratus beetles from six populations in South Carolina and Georgia were individually macerated in glass tissue grinders and serially diluted to quantify the CFU of fungal symbionts. Six species of Raffaelea were isolated, with up to four species from an individual adult beetle. The Raffaelea spp. were apparently within the
\end{abstract}

protected, paired, mandibular mycangia because they were as numerous in heads as in whole beetles, and surface-sterilized heads or whole bodies yielded as many or more CFU as did nonsterilized heads or whole beetles. $R$. lauricola was isolated from 40 of the 41 beetles sampled, and it was isolated in the highest numbers, up to $30,000 \mathrm{CFU} / \mathrm{beetle}$. Depending on the population sampled, $R$. subalba or R. ellipticospora was the next most frequently isolated species. $R$. arxii, $R$. fusca, and $R$. subfusca were only occasionally isolated. The laurel wilt pathogen apparently grows in a yeast phase within the mycangia in competition with other Raffaelea spp.

Additional keywords: Candida spp., Curculionidae, Lauraceae, Persea borbonia, Scolytinae, vector.
Laurel wilt is a new, lethal disease on redbay (Persea borbonia) and other members of the family Lauraceae, including Sassafras albidum and commercial avocado ( $P$. americana), in the southeastern United States $(6,18)$. This vascular wilt disease is caused by an ambrosia beetle symbiont, Raffaelea lauricola T. C. Harrin., Aghayeva, \& Fraedrich (14). The primary vector of $R$. lauricola is the redbay ambrosia beetle, Xyleborus glabratus Eichh., which was most likely introduced from Asia to the Savannah, GA area in solid wood packing material $(6,19)$. The redbay ambrosia beetle is native to Asia (e.g., India, Japan, and Taiwan), where it infests aromatic tree species, especially species in the family Lauraceae (25). It is assumed that the beetle brought $R$. lauricola with it to the United States (14).

Although it has been suggested that a fungal associate of Platypus quercivora (Murayama) may aid the beetle in killing mass-attacked trees (17), ambrosia beetle symbionts have not been considered plant pathogens. $R$. lauricola is unusual in that it is the first ambrosia beetle symbiont known to cause a lethal vascular wilt disease $(6,14)$. X. glabratus is unusual among ambrosia beetles in that it is not attracted to ethanol but is instead attracted to host plant volatiles (9). This attraction to host volatiles is believed to be important in its occasional attacks on live trees, thus providing the opportunity to introduce $R$. lauricola into healthy, susceptible plant hosts (6). Like other species of Xyleborus, $X$. glabratus has paired sacs near its mandibles, and these sacs, called mycangia, contain fungal spores (6). Budding yeast-

Corresponding author: T. C. Harrington, E-mail address: tcharrin@ iastate.edu

doi:10.1094/PHYTO-01-10-0032

This article is in the public domain and not copyrightable. It may be freely reprinted with customary crediting of the source. The American Phytopathological Society, 2010. like spores, believed to be those of $R$. lauricola, were observed within the mycangia of $X$. glabratus (6).

Ambrosia beetles (Coleoptera: Curculionidae: Scolytinae and Platypodinae) are a polyphyletic, ecologically defined group of $\approx 3,400$ species derived from bark beetles (5). Adults generally bore galleries and lay eggs in the nutrient-poor sapwood of dead or dying trees. Fungal symbionts grow in the sapwood and produce an "ambrosia" (food of the gods) of asexual spores (conidia) from tightly packed conidiophores, and the adults and larvae feed on the conidia $(1,7,12,22)$. The fungi are usually carried from tree to tree by the adults in mycangia and, in some cases, it has been suggested that the fungal symbionts grow and multiply in a yeast phase within the mycangium due to secretions from surrounding gland cells $(1,3,7)$.

A number of ambrosia beetle symbionts have been isolated from ambrosia beetle galleries and directly from mycangia $(1,7,15)$, though this work has been tedious, and there is much to learn about the fungal symbionts of ambrosia beetles. Generally, isolations have been done on only a few individual beetles, and only a single or a few fungal symbionts have been associated with a particular ambrosia beetle species $(1,2,8)$. Many of the tightly associated symbionts have been described in the asexual genera Raffaelea and Ambrosiella, which are phylogenetically placed within the sexual genera Ophiostoma and Ceratocystis, respectively (12). Other fungi, especially yeasts, have been associated with ambrosia beetles and their galleries $(2,3)$ but these species may not form good ambrosia growth for feeding by the insects (12).

The larvae and adults of $X$. glabratus presumably feed on conidia of $R$. lauricola, and young females may acquire spores in their mycangia during feeding. $R$. lauricola can be readily isolated from the head but not from the abdomen or thorax of adult female $X$. glabratus (6). Males of Xyleborus spp. are much smaller than females, generally flightless, and typically mate with 
their siblings before the young females emerge (19). Thus, only female $X$. glabratus serve as important vectors of $R$. lauricola (6). When populations of $X$. glabratus are high, aborted attacks on healthy redbay are common, and it is believed that conidia of $R$. lauricola are introduced into healthy trees during such aborted attacks (6). After a single introduction into a susceptible redbay, the pathogen may move systemically throughout the tree in the xylem vessels and kill the tree within weeks or months, providing brood material for egg-laying attacks.

In order to better understand the relationship between pathogen and vector, we deployed a dilution plating technique $(11,12)$ to quantify the number of CFU of fungal symbionts in adult females of the redbay ambrosia beetle. Colonies of differing morphology that developed on the isolation plates were quantified, representatives were transferred to new plates, and 26S rDNA sequences were determined to group them into putative species (13). In addition to $R$. lauricola and $R$. arxii, four new Raffaelea spp. were isolated and described (13). Here, we report on the number of CFU of these species recovered from 41 beetles collected from six sites in South Carolina and Georgia.

\section{MATERIALS AND METHODS}

Adult, female $X$. glabratus beetles were collected from sites on the Atlantic coastal plains of Georgia and South Carolina during 2006 and 2007. Beetle collections from Hunting Island, SC were made in October 2006 and an additional collection from Hunting Island was made in December 2006. The Jesup, GA collection was in October 2006. A collection was made on Plum Creek Timber Company lands near Nahunta, GA in March 2007. The collections from Jekyll Island, Sapelo Island, and Clyo, GA were made in July 2007.

Beetle collection. In most cases, young females were excavated from the sapwood of infested redbay trees that were recently killed by laurel wilt. Sections of the main stem of diseased and infested redbay were brought to the laboratory and dissected to expose the cross-sections of tunnels. Typically, a piece of narrowdiameter wire was used to push the adult beetles from the tunnels. It could not be determined for certain whether the female adults were egg-laying adults that had bored into the tree or if they were young females that had not yet emerged. Most of the females were likely the latter, though no teneral (light-colored) females were used. Female beetles were refrigerated until isolation attempts were made, usually within 1 week.

The December 2006 collection from Hunting Island comprised beetles that had emerged in the laboratory (reared) from bolts taken from infested and diseased redbay. The bolts were placed in plastic rearing chambers to which test tubes were attached to serve as light traps and collection points for the beetles. Emerged adults were collected every few days and processed the same day or placed in a refrigerator until isolations were attempted.

The beetles collected at Plum Creek were obtained in flight (airborne) on 12 March 2007. These beetles were presumed to be newly emerged from diseased redbay and were individually captured in vials as they landed on tree stumps and exposed surfaces of cut branches or clothing. The beetles were apparently attracted to fresh wounds on redbay trees that were created during our sampling of redbay trees. Beetles were stored on ice and then in a refrigerator until plated.

Surface sterilization, grinding, and dilution plating. A dilution plating technique $(11,12)$ was used to quantify the number of CFU per female beetle. Some females were decapitated and only the head used for isolations. Otherwise, whole beetles were ground and the slurry serially diluted. Some heads or whole beetles were surface sterilized prior to grinding for $3 \mathrm{~min}$ in $15 \mathrm{ml}$ of $0.6 \%$ sodium hypochlorite with two drops of Tween 80 (or $0.6 \%$ sodium hypochlorite with $0.1 \%$ Tween 80 ) and then rinsed three times in sterile, deionized water before grinding. The head or the whole adult female was ground in 2-ml glass tissue grinders with $200 \mu \mathrm{l}$ of sterile deionized water and, after thorough maceration, another $1.8 \mathrm{ml}$ of sterile deionized water was added and further ground and mixed for $\approx 1 \mathrm{~min}$. After grinding, aliquots of the slurry were serially diluted in sterile deionized water to $20 x$ and $200 \times$, and $200 \mu \mathrm{l}$ (Hunting Island and Jesup collections on October 2006) or $100 \mu \mathrm{l}$ of the dilution (all other isolations) was added to the surface of the agar medium in $100-\mathrm{mm}$ petri plates and spread with a flame-sterilized, bent glass rod. Each dilution was added to three petri plates.

Isolation media. Most isolations were made on CSMA medium $(1.0 \%$ malt extract and $1.5 \%$ agar, with cycloheximide at $200 \mathrm{ppm}$ and streptomycin sulfate at $100 \mathrm{ppm}$ added after autoclaving), which is semiselective for Ophiostoma spp. and related anamorphs such as Raffaelea spp. $(4,10,11)$. Dilutions of beetles from Jekyll Island, Sapelo Island, and Clyo were also plated on STMA (1.0\% malt extract, $1.5 \%$ agar, streptomycin at $100 \mathrm{ppm}$ added after autoclaving, and $0.01 \%$ tergitol) and SMA (malt extract agar with streptomycin at $100 \mathrm{ppm}$ ) to compare the effectiveness of the media and to determine whether the beetles carried additional fungal symbionts that did not tolerate cycloheximide.

Identification and quantification of CFU. Dilution plates were examined for 1 to 4 weeks for the presence of fungal colonies. Colonies of different size, color, and mycelial pattern (concentric rings, yeasty centers, hyaline margins, and so on) were considered putative species. If the number of colonies of a putative species exceeded 25 per plate on the $20 \times$ plates, then the $200 \times$ plates were used for counting colonies. The CFU/head or whole beetle for each putative fungal species were expressed as a mean of the three plates of the appropriate dilution, and the mean was considered a single replicate. The standard error of the mean (SE) $(P=0.05$, standard deviation divided by the square root of the number of beetles in the sample) was calculated for various treatments or collections of beetles. Means of populations or treatments were compared with paired or unpaired $t$ tests (twotailed, homogeneous variances) with a $P=0.05$ threshold.

Subcultures of colonies of different morphologies were made to identify the putative species. Sequencing of a portion of the large subunit (LSU) of rDNA (13) was done on at least one representative of each colony morphotype from each beetle collection to confirm the putative identification.

\section{RESULTS}

Six species of fungi were isolated from the 41 female $X$. glabratus adults on CSMA. The six species could be distinguished by the color and texture of their mycelia and their relative growth rate, as illustrated previously (13). The partial LSU sequences of the six species (EU177438 to EU177451, EU177455 to EU177456) matched precisely those of $R$. lauricola, $R$. arxii Scott $\&$ du Toit, or one of the four recently described species of Raffaelea (13). For each of the six species, there was no variation in the respective LSU sequence.

Hunting Island and Jesup isolations. The October collections of beetles from Hunting Island and Jesup were treated similarly and the results combined in Table 1 because there was no substantial difference in the CFU of the Raffaelea spp. isolated. Four whole females (three from Hunting Island and one from Jesup) excavated from infested and wilted redbay trees in October were ground without prior surface sterilization, and 100 to 3,000 CFU of $R$. lauricola were recovered on CSMA, with a mean of 1,158 CFU/beetle (Table 1). R. subalba T. C. Harrin., Aghayeva \& Fraedrich was also isolated from all four beetles at 367 to 1,000 $\mathrm{CFU} /$ beetle, mean $=692 \mathrm{CFU}$ (Table 1). R. subfusca T. C. Harrin., Aghayeva \& Fraedrich was isolated from two of the four beetles that were not surface sterilized; one yielded $133 \mathrm{CFU}$ and the other yielded $367 \mathrm{CFU}$. 
The whole bodies of three beetles collected in October (two from Jesup and one from Hunting Island) were first surface sterilized prior to grinding and dilution, and each yielded $R$. lauricola, with a mean of 1,189 CFU/beetle, similar to the level recovered from whole beetles that were not surface sterilized (Table 1). R. subalba was also isolated from the three surfacesterilized beetles at approximately the same number of CFU as from the beetles that were not surface sterilized (Table 1). One of the three surface-sterilized beetles yielded $167 \mathrm{CFU}$ of $R$. subfusca.

The heads of beetles excavated from bolts in October (one beetle from Hunting Island and one from Jesup) or reared from bolts in December (three from Hunting Island) were individually ground, and $R$. lauricola was recovered from four of the five heads at 2,000 to $6,000 \mathrm{CFU} /$ head (Table 1). There was no difference in the number of CFU of $R$. lauricola between the October (excavated beetles) and December collections (reared beetles). R. subalba was isolated from all five heads at 400 to 2,600 CFU/beetle (Table 1) but significantly more CFU $(P=$ $0.032)$ were recovered from the heads of reared beetles $(1,600$, 2,000 , and 2,600 CFU, respectively) than from the heads of the excavated beetles (400 and 733 CFU, respectively).

Nine heads (three from beetles collected from Jesup in October, one collected at Hunting Island in October, and five collected from Hunting Island in December) were individually ground after surface sterilization. $R$. lauricola was isolated from each of the nine heads at 967 to $10,000 \mathrm{CFU} /$ head (Table 1). $R$. subalba was isolated from eight of nine surface-sterilized heads at 133 to 2,133 $\mathrm{CFU} /$ beetle. There was no significant difference between the October and December collections in the CFU of either Raffaelea spp.. In a paired $t$ test of CFU from the nine heads, the number of CFU of $R$. lauricola was higher than the CFU of $R$. subalba $(P=$ 0.001).

There was no significant difference between the CFU of $R$. lauricola or $R$. subalba recovered from the five heads that were not surface sterilized versus the nine heads that were surface sterilized (Table 1). The other Raffaelea spp. (R. ellipticospora T. C. Harrin., Aghayeva \& Fraedrich, R. subfusca, R. fusca T. C. Harrin., Aghayeva \& Fraedrich, and $R$. arxii) were only isolated from surface-sterilized heads (Table 1). The two beetles from which $R$. ellipticospora was isolated were from Hunting Island. One individual head that was surface sterilized yielded $R$. lauricola (5,500 CFU), R. ellipticospora (1,000 CFU), R. subfusca (333 CFU), and $R$. subalba (133 CFU).

Isolations from heads-only tended to yield more CFU of Raffaelea spp. than isolations from whole beetles (Table 1). Although there was no significant difference between the CFU of $R$. lauricola or $R$. subalba recovered from the whole beetles versus heads only that were not surface sterilized, the number of CFU of $R$. lauricola recovered from the surface-sterilized heads was significantly greater $(P=0.030)$ than the CFU recovered from whole bodies that were surface sterilized. The number of CFU of
$R$. subalba was also greater from the surface-sterilized heads than from the whole beetles that were surface sterilized (Table 1) but the difference was not statistically significant. $R$. ellipticospora, $R$. arxii, and $R$. fusca were only isolated from surface-sterilized heads and not from whole beetles (Table 1).

Combining all the isolations from beetles collected at Hunting Island and Jesup, $R$. lauricola was isolated from 20 of the 21 beetles (mean $=3,595 \mathrm{CFU} /$ beetle). The number of CFU of $R$. lauricola was significantly greater in a paired $t$ test $(P<0.001)$ than the number of CFU of $R$. subalba (mean $=977 \mathrm{CFU}$ ), which was also isolated from 20 of the 21 the beetles. The other Raffaelea spp. were infrequently isolated from the beetles collected at Hunting Island and Jesup (Table 1).

Plum Creek isolations. The adult females from Plum Creek were collected individually in vials as they landed on the surfaces of wounded or cut redbay trees or on the clothing of individuals who were examining diseased and healthy-appearing redbay on a warm, still day in March 2007, early in the flight season (9). Nine beetles were ground whole after surface sterilization and plated on CSMA. Only two Raffaelea spp. were isolated. R. lauricola was isolated from all nine beetles at 3,134 to 30,000 CFU/beetle, and $R$. ellipticospora was isolated from six of the beetles at 667 to 3,666 CFU/beetle (Table 1). The three beetles for which only one species of Raffaelea was recovered had 3,134, 26,667, and 30,000 CFU, respectively, of $R$. lauricola. For all nine beetles, the number of CFU of $R$. lauricola was greater than the number of CFU of $R$. ellipticospora in a paired $t$ test $(P=0.001)$.

Two other female beetles collected at Plum Creek were not surface sterilized before grinding, diluting, and plating on CSMA (data not shown), and they yielded $R$. lauricola (3,066 and 4,667 CFU/beetle, respectively) and $R$. ellipticospora (800 and 267 $\mathrm{CFU} /$ beetle, respectively). The differences in the CFU of $R$. lauricola or R. ellipticospora were not significantly different between the whole beetles that were surface sterilized versus those that were not surface sterilized.

In comparing the three surface-sterilized, whole beetles from the October collection (one beetle from Hunting Island and two from Jesup) versus the nine surface-sterilized beetles captured in flight in March (from the Plum Creek site), significantly more CFU of $R$. lauricola $(P=0.019)$ were recovered from the beetles collected in flight at Plum Creek (mean $=1,189$ versus 16,200 CFU/beetle, respectively) (Table 1).

Isolations on different media. Further isolations were conducted on STMA, which restricts bacteria and suppresses growth of filamentous fungi, respectively; on SMA, containing streptomycin, versus CSMA, containing streptomycin and cycloheximide, which limits the growth of most fungi and favors isolation of species of Ophiostoma, Raffaelea, and related genera $(4,10,11)$. Three beetles from each of three sites were excavated from infested bolts of redbay in July 2007 and ground as above, and the dilutions from the beetles were plated on the three media. $R$. lauricola was isolated from each of the nine beetles, regardless

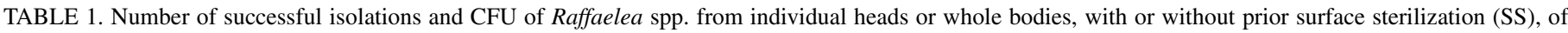

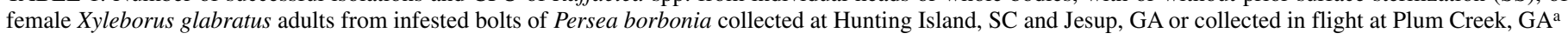

\begin{tabular}{|c|c|c|c|c|c|c|c|c|c|c|c|c|c|c|}
\hline \multirow[b]{2}{*}{ Location, date collected } & \multirow[b]{2}{*}{ Part $^{\mathrm{b}}$} & \multirow[b]{2}{*}{$\mathrm{SS}$} & \multicolumn{2}{|c|}{ Raffaelea lauricola } & \multicolumn{2}{|c|}{ R. subalba } & \multicolumn{2}{|c|}{ R. ellipticospora } & \multicolumn{2}{|c|}{ R. subfusca } & \multicolumn{2}{|c|}{ R. arxii } & \multicolumn{2}{|c|}{ R. fusca } \\
\hline & & & No. & $\mathrm{CFU} \pm \mathrm{SE}$ & No. & $\mathrm{CFU} \pm \mathrm{SE}$ & No. & $\mathrm{CFU} \pm \mathrm{SE}$ & No. & $\mathrm{CFU} \pm \mathrm{SE}$ & No. & $\mathrm{CFU} \pm \mathrm{SE}$ & No. & $\mathrm{CFU} \pm \mathrm{SE}$ \\
\hline \multicolumn{15}{|l|}{$\begin{array}{l}\text { Hunting Island and } \\
\text { Jesup }\end{array}$} \\
\hline Oct. 06 & Whole & No & $4 / 4$ & $1,158 \pm 637$ & $4 / 4$ & $692 \pm 153$ & $0 / 4$ & 0 & $2 / 4$ & $125 \pm 87$ & $0 / 4$ & 0 & $0 / 4$ & 0 \\
\hline Oct. 06 & Whole & Yes & $3 / 3$ & $1,189 \pm 110$ & $3 / 3$ & $533 \pm 135$ & $0 / 3$ & 0 & $1 / 3$ & $56 \pm 56$ & $0 / 3$ & 0 & $0 / 3$ & 0 \\
\hline Oct. and Dec. 06 & Head & No & $4 / 5$ & $3,700 \pm 1,221$ & $5 / 5$ & $1,466 \pm 404$ & $0 / 5$ & 0 & $0 / 5$ & 0 & $0 / 5$ & 0 & $0 / 5$ & 0 \\
\hline Oct. and Dec. 06 & Head & Yes & $9 / 9$ & $5,422 \pm 936$ & $8 / 9$ & $979 \pm 247$ & $2 / 9$ & $185 \pm 126$ & $3 / 9$ & $274 \pm 219$ & $1 / 9$ & $74 \pm 74$ & $1 / 9$ & $74 \pm 74$ \\
\hline \multicolumn{15}{|l|}{ Plum Creek } \\
\hline March 07 & Whole & Yes & $9 / 9$ & $16,200 \pm 2,989$ & $0 / 9$ & 0 & $6 / 9$ & $1,400 \pm 481$ & $0 / 9$ & 0 & $0 / 9$ & 0 & $0 / 9$ & 0 \\
\hline
\end{tabular}

${ }^{\mathrm{a}}$ No. $=$ number of successful isolations of the species/number of beetles sampled and CFU $\pm \mathrm{SE}=$ mean $\mathrm{CFU} \pm$ standard error $(\mathrm{SE})$.

b Head only or whole beetle. 
of the isolation medium, though the greatest number of CFU were on CSMA and the least on STMA (Table 2). In paired $t$ tests, the CFU of $R$. lauricola counted on SMA and CSMA were greater than on STMA ( $P=0.031$ and $P=0.027$, respectively) but there was no significant difference between the number of CFU of $R$. lauricola on SMA versus CSMA $(P=0.056)$. Isolation medium had no significant effect on the numbers of CFU of the other Raffaelea spp. (Table 2).

$R$. subalba was isolated from one of the three beetles collected at Jekyll Island, three of the three beetles from Sapelo Island, and two of the three beetles from Clyo (Table 2). Comparing isolations on CSMA only, the number of CFU of $R$. lauricola did not differ among the three sites but the number of CFU of $R$. subalba was greater at the Sapelo Island site than at the Jekyll Island site $(P=0.027)$ and at the Clyo site $(P=0.026)$. The number of CFU of $R$. lauricola was greater than the CFU of $R$. subalba at Jekyll Island $(P=0.044)$. However, when beetles from all three sites were combined, a paired $t$ test showed that there was no significant difference $(P=0.059)$ between the numbers of CFU of $R$. lauricola versus $R$. subalba on CSMA medium.

$R$. ellipticospora was not isolated from the beetles collected at the Sapelo Island and Clyo sites but it was isolated from two of the three beetles from Jekyll Island, where R. ellipticospora was the second most numerous Raffaelea spp. and where there was no difference $(P=0.055)$ between the CFU of $R$. lauricola versus $R$. ellipticospora. $R$. arxii was isolated from only the three beetles at Clyo, where there was no significant difference between the CFU of $R$. lauricola, $R$. subalba, or $R$. arxii (Table 2). R. subfusca was isolated from one beetle collected at each of the three sites (Table 2). R. fusca was not isolated from any of the beetles collected at the three sites.

In addition to the Raffaelea spp., at least two species of yeast were isolated from the nine beetles collected at the three sites but only on STMA and SMA media (Table 2). Unidentified Candida spp. were isolated on STMA and SMA from one beetle collected at Jekyll Island (14,000 CFU on STMA), two beetles collected at Sapelo Island (14,600 CFU from one of the beetles on SMA), and two beetles from Clyo (466 and 6,666 CFU on STMA, respectively). A portion of the LSU rDNA was amplified and sequenced from two representative yeast cultures isolated from beetles collected at the Clyo site (GenBank accession numbers HM364287 and HM364288). The closest matches to these respective sequences using BLAST searches (v. 2.2.23+; National Center for Biotechnology Information, National Institute of Health) were Pichia sydowiorum (D. B. Scott \& van der Walt) Kurtzman (anamorph: Candida nitrativorans van der Walt, D. B. Scott \& van der Klift; GenBank accession number EF550343; 676 of 681 bp matching) and an unidentified Candida sp. (strain NRRL Y27127, GenBank accession number EF550293, 681 of 681 bp matching).

\section{DISCUSSION}

The laurel wilt pathogen was isolated from 40 of 41 sampled beetles and in numbers of CFU consistent with the hypothesis that it grows in a yeast phase within the mycangia of X. glabratus (6). Although $R$. lauricola was the most consistently isolated and abundant Raffaelea sp., it is only one of six potential fungal symbionts of this ambrosia beetle in the southeastern United States. The Raffaelea spp. were recovered from heads of $X$. glabratus in as high or higher CFU as from whole beetles, and surface sterilization of heads or whole beetles did not reduce the number of CFU. Thus, the Raffaelea spores were likely contained within the protected, mandibular mycangia.

The mycangia of $X$. glabratus are roughly spherical, $\approx 60 \mu \mathrm{m}$ in diameter, and tightly packed with spores (6). Although gland cells around the mycangia were not identified (6), similar mycangia in other ambrosia beetles are filled with glandular secretions that may foster growth and budding of fungal spores $(1,3,7)$. Conidia of $R$. lauricola vary greatly in size (14) but, assuming the size of the smallest spores ( 3.5 by 1.5 by $1.5 \mu \mathrm{m})$, nearly 15,000 conidia of $R$. lauricola could be packed into one of the paired mycangia. The estimates of spore numbers of the Raffaelea spp. from $X$. glabratus are conservative because the grinding was not complete, some of the spores may have adhered to beetle tissue or to the glass walls of the grinders, and some of the spores were likely killed in the storage of the beetles and in the grinding process. Nonetheless, thousands of viable spores of Raffaelea spp. were recovered from individual, surface-sterilized heads of $X$. glabratus. The high number of CFU of $R$. lauricola, $\leq 30,000 \mathrm{CFU}$, would only seem possible if the mycangia were tightly packed due to a budding yeast phase (6). Sporulation within mycangia would appear to be an important adaptation for the fungal symbionts $(12,13)$, and competition among the Raffaelea spp. may be keen.

The number of CFU of $R$. lauricola was particularly high in the Plum Creek sample, where the beetles were captured in flight; that is, after there had been time for the fungus to bud profusely in the mycangium. It is assumed that, after filling the mycangium, the budding spores of Raffaelea spp. continue to bud and ooze out of the mycangia, thus inoculating the sapwood as the females bore galleries for egg laying. In aborted tunnels in the sapwood of healthy trees (6), thousands of spores of $R$. lauricola may ooze from the mycangia and infect the severed vessels, resulting in systemic colonization of the host plant.

TABLE 2. Number of CFU of Raffaelea and Candida spp. from dilution plating onto three isolation media of individual, female Xyleborus glabratus beetles collected at three sites ${ }^{\mathrm{a}}$

\begin{tabular}{|c|c|c|c|c|c|c|c|c|c|c|c|c|}
\hline \multirow[b]{2}{*}{ Location, medium $^{\mathrm{b}}$} & \multicolumn{2}{|c|}{ Raffaelea lauricola } & \multicolumn{2}{|c|}{ R. subalba } & \multicolumn{2}{|c|}{ R. ellipticospora } & \multicolumn{2}{|c|}{ R. subfusca } & \multicolumn{2}{|c|}{ R. arxii } & \multicolumn{2}{|c|}{ Candida spp. } \\
\hline & No. & $\mathrm{CFU} \pm \mathrm{SE}$ & No. & $\mathrm{CFU} \pm \mathrm{SE}$ & No. & $\mathrm{CFU} \pm \mathrm{SE}$ & No. & $\mathrm{CFU} \pm \mathrm{SE}$ & No. & $\mathrm{CFU} \pm \mathrm{SE}$ & No. & $\mathrm{CFU} \pm \mathrm{SE}$ \\
\hline \multicolumn{13}{|l|}{ Jekyll Island } \\
\hline STMA & $3 / 3$ & $3,578 \pm 2,213$ & $1 / 3$ & $267 \pm 267$ & $2 / 3$ & $867 \pm 677$ & $1 / 3$ & $200 \pm 200$ & $0 / 3$ & 0 & $1 / 3$ & $4,667 \pm 4,667$ \\
\hline CSMA & $3 / 3$ & $8,488 \pm 2,576$ & $1 / 3$ & $711 \pm 711$ & $2 / 3$ & $1,267 \pm 796$ & $1 / 3$ & $311 \pm 311$ & $0 / 3$ & 0 & $0 / 3$ & 0 \\
\hline \multicolumn{13}{|l|}{ Sapelo Island } \\
\hline STMA & $3 / 3$ & $1,355 \pm 374$ & $3 / 3$ & $5,333 \pm 1,333$ & $0 / 3$ & 0 & $1 / 3$ & $267 \pm 267$ & $0 / 3$ & 0 & $1 / 3$ & $2,156 \pm 2,156$ \\
\hline STMA & $3 / 3$ & $978 \pm 678$ & $2 / 3$ & $467 \pm 234$ & $0 / 3$ & 0 & $1 / 3$ & $133 \pm 133$ & $3 / 3$ & $467 \pm 234$ & $2 / 3$ & $2,377 \pm 2,148$ \\
\hline SMA & $3 / 3$ & $3,667 \pm 2,509$ & $1 / 3$ & $155 \pm 155$ & $0 / 3$ & 0 & $1 / 3$ & $155 \pm 155$ & $3 / 3$ & $778 \pm 309$ & $2 / 3$ & $3,933 \pm 3,703$ \\
\hline CSMA & $3 / 3$ & $5,333 \pm 4,019$ & $2 / 3$ & $756 \pm 690$ & $0 / 3$ & 0 & $0 / 3$ & 0 & $3 / 3$ & $755 \pm 256$ & $0 / 3$ & 0 \\
\hline
\end{tabular}

${ }^{a}$ No. $=$ number of successful isolations of the species/number of beetles sampled and CFU $\pm \mathrm{SE}=$ mean CFU \pm standard error (SE).

${ }^{\mathrm{b}}$ Dilutions of ground beetles were plated on three media: STMA = malt extract agar with streptomycin and tergitol, SMA = streptomycin malt agar, and CSMA = cycloheximide and streptomycin agar. 
Another vascular wilt pathogen, Ophiostoma novo-ulmi Brasier, has bark beetle (Curculionidae: Scolytinae) vectors but the beetles are less efficient at transmitting the pathogen to susceptible trees. The cause of Dutch elm disease produces sticky spore drops on stalks in the galleries of bark beetles that develop in wilted trees, and the spores are acquired externally on the young adults. With the vector Scolytus multistriatus (Marsham), $\leq 57,000$ CFU of $O$. novo-ulmi may be recovered from a single beetle; however, not all beetles acquire the pathogen and, because there is no mycangium, the number of beetles carrying the pathogen declines rapidly after emergence (24). The pathogen may be transmitted to healthy trees through feeding in the crotches of twigs, and infection may occur if the feeding wound severs vessels in the xylem and spores infect the vessels. However, even if the beetles are carrying the pathogen, fewer than $15 \%$ of the feeding sites are infected (24). In contrast, virtually all female $X$. glabratus beetles carry thousands of spores of $R$. lauricola that presumably ooze from the mycangia and potentially infect the severed vessels along the sapwood tunnels.

Other studies have examined the frequency of association of ambrosia beetle symbionts with ambrosia beetles (15) but a search of the literature failed to find comparable quantification of fungal propagules from ambrosia beetles. However, comparable quantification of fungi from a bark beetle was made (12). Female adults of the southern pine beetle (SPB) (Dendroctonus frontalis Zimmermann) have a relatively large pronotal mycangium that may contain either an ascomycete (Ceratocystiospsis ranaculosus Bridges \& Perry) or a basidiomycete (Entomocorticium sp. A). Both fungi are nutritional symbionts of SPB larvae, and isolations from mycangia showed a negative correlation between the incidence of the two species in SPB populations (12). C. ranaculosus produces short conidiophores and a budding yeast phase in the mycangium. Sampled populations of SPB reared from infested bolts had an average of 10,000 to 70,000 CFU of $C$. ranaculosus per female beetle (12), greater than but comparable with the highest numbers of CFU of $R$. lauricola recovered from $X$. glabratus, which has much smaller mycangia. O. minus (Hedgecock) H. \& P. Sydow and O. nigrocarpum (R. W. Davidson) de Hoog, which are not mycangial, were isolated in hundreds of CFU rather than tens of thousands of CFU/beetle (12). Filamentous bacteria (actinomycetes) that are inhibitory to some fungi in culture may be isolated from mycangia of female SPB (21). The complex interactions among the diverse components of the microflora of SPB $(12,16)$ suggest that microbial associations of the redbay ambrosia beetle also will prove to be complex.

Ambrosia beetles have generally been thought to be tightly associated with one or only a few symbiotic fungi $(1,2,8)$; however, six Raffaelea spp. were isolated from X. glabratus, and up to four species were isolated from the head of a single surfacesterilized beetle. This diversity of Raffaelea spp. is particularly surprising because the sampled $X$. glabratus populations are thought to have gone through a narrow population bottleneck with the single introduction of $X$. glabratus from Asia to the Savannah, GA area, from where the beetle has spread to South Carolina and Florida $(6,19)$. Further, the beetle is breeding almost exclusively in trees with laurel wilt, and the trees are well colonized by $R$. lauricola prior to egg-laying attacks $(6,9)$. This should favor sporulation of $R$. lauricola over the other Raffaelea spp. in the galleries and, thus, favor entry of $R$. lauricola into the mycangia during feeding.

The associates of $X$. glabratus in Asia have not yet been reported but it is assumed that $R$. lauricola and at least some of the other Raffaelea spp. are also tightly associated with the beetle in Asia (13). Previously, $R$. arxii had been associated with only $X$. torquatus Eichh. in South Africa (20), and the other four species of Raffaelea are only known from this study of $X$. glabratus symbionts (13). It is possible that some of these Raffaelea spp. are symbionts with other ambrosia beetles native or exotic to the southeastern United States and that $R$. lauricola could form a symbiotic relationship with other ambrosia beetle species.

Ambrosial beetle symbionts are poorly known, though most of the recognized species are asexual Ophiostoma spp. that are placed in the genus Raffaelea, which has 19 described species (13). In addition to Raffaelea, species of Ambrosiella are common fungal symbionts of ambrosia beetles. Ambrosiella spp. are asexual Ceratocystis spp. and do not tolerate cycloheximide $(4,13)$. Ambrosiella spp. were not isolated from X. glabratus on STMA or SMA, media that should have allowed their growth. In contrast, isolations from two other exotic ambrosia beetles on redbay, Xylosandrus compactus (Eichh.) and X. crassiusculus (Motschulsky) (6), have yielded Ambrosiella but not Raffaelea spp. (2) (unpublished data). We have isolated $R$. lauricola from Xyleborinus saxeseni (Ratzeburg) adults, and this beetle also has been associated with a Raffaelea sp., R. sulphurea (Batra) T. C. Harrin. $(2,13)$. It is possible that the mycangial secretions of some ambrosia beetles favor Raffaelea or Ambrosiella spp. but not both.

Yeasts were isolated from Xyleborus glabratus on media that did not contain cycloheximide but it is not likely that these yeasts are important mycangial symbionts of the beetle. Candida and Pichia spp. have been frequently associated with beetles, especially as part of the gut microflora of beetles (23). High numbers of CFU of yeasts and Raffaelea spp. from an individual beetle suggest that the yeasts were inhabiting the gut and not the mycangia. Candida spp. are not known to produce luxurious growth of conidia on conidiophores in a compact fruiting structure (sporodochium) for insect grazing, an important feature for fungal symbionts of mycophagous bark and ambrosia beetles $(1,12)$. Likewise, we did not sample for bacteria, which may possibly inhabit the mycangia of ambrosia beetles, but bacteria would not likely produce suitable ambrosial growth for beetle feeding.

Some of the substantial variation found among the six populations of X. glabratus in the number of CFU of R. lauricola and the other species may have been due to month of sampling, maturity of the beetles, or the extent of colonization of the trees by $R$. lauricola prior to beetle attack and brood emergence. Beetles that develop in redbay killed by other causes may carry fewer spores of $R$. lauricola, and other species of Raffaelea may be favored when beetles develop in other hosts. Antagonism and competition among Raffaelea spp., yeasts, insect pathogens, fungal pathogens, or other microbes within the tunnels and mycangia could result in lower numbers of spores of $R$. lauricola in some circumstances. Biological control of the pathogen may prove possible through manipulation of the mycangial microflora. However, with such consistently high numbers of CFU of $R$. lauricola in the mycangia of virtually all $X$. glabratus beetles, incidence of laurel wilt in redbay would appear to be limited only by the population level of the beetle, on which disease management should focus.

\section{ACKNOWLEDGMENTS}

We thank J. Steimel, S. Lumpkin, and S. Best for their excellent technical assistance; and C. Bates, J. Johnson, and J. Beck (Georgia Forestry Commission), who were instrumental in locating laurel wilt study sites.

\section{LITERATURE CITED}

1. Batra, L. R. 1963. Ecology of ambrosia fungi and their dissemination by beetles. Trans. Kansas Acad. Sci. 66:213-236.

2. Batra, L. R. 1967. Ambrosia fungi: a taxonomic revision and nutritional studies of some species. Mycologia 59:976-1017.

3. Beaver, R. A. 1989. Insect-fungus relationships in the bark and ambrosia beetles. Pages 121-143 in: Insect-Fungus Interactions. N. Wilding, N. M. Collins, P. M. Hammond, and J. F. Webber, eds. Academic Press, London.

4. Cassar, S., and Blackwell, M. 1996. Convergent origins of ambrosia fungi. Mycologia 88:596-601. 
5. Farrell, B. D., Sequeira, A. S., O’Meara, B. C., Normark, B. B., Chung, J. H., and Jordal, B. H. 2001. The evolution of agriculture in beetles (Curculionidae: Scolytinae and Platypodinae). Evolution 55:2011-2027.

6. Fraedrich, S. W., Harrington, T. C., Rabaglia, R. J., Ulyshen, M. D., Mayfield, A. E., Hanula, J. L., Eickwort, J. M., and Miller, D. R. 2008. A fungal symbiont of the redbay ambrosia beetle causes a lethal wilt in redbay and other Lauraceae in the southeastern United States. Plant Dis. 92:215-224.

7. Francke-Grosmann, H. 1967. Ectosymbiosis in wood-inhabiting insects. Pages 142-206 in: Symbiosis, Vol. 11. S. M. Henry, ed. Academic Press, New York.

8. Funk, A. 1970. Fungal symbionts of the ambrosia beetle Gnathotrichus sulcatus. Can. J. Bot. 48:1445-1448.

9. Hanula, J. L., Mayfield, A. E., Fraedrich, S. W., and Rabaglia, R. J. 2008. Biology and host associations of the redbay ambrosia beetle (Coleoptera: Curculionidae: Scolytinae), exotic vector of laurel wilt killing redbay trees in the southeastern United States. J. Econ. Entomol. 101:1276-1286.

10. Harrington, T. C. 1981. Cycloheximide sensitivity as a taxonomic character in Ceratocystis. Mycologia 73:1123-1129.

11. Harrington, T. C. 1992. Leptographium. Pages 129-133 in: Methods for Research on Soilborne Phytopathogenic Fungi. L. L. Singleton, J. D. Mihail, and C. M. Rush, eds. American Phytopathological Society Press, St. Paul, MN.

12. Harrington, T. C. 2005. Ecology and evolution of mycophagous bark beetles and their fungal partners. Pages 257-292 in: Insect-Fungal Associations: Ecology and Evolution. F. E. Vega and M. Blackwell, eds. Oxford University Press, Inc., New York.

13. Harrington, T. C., Aghayeva, D. N., and Fraedrich, S. W. 2010. New combinations in Raffaelea, Ambrosiella, and Hyalorhinocladiela, and four new species from the redbay ambrosia beetle, Xyleborus glabratus. Mycotaxon 111:337-361.

14. Harrington, T. C., Fraedrich, S. W., and Aghayeva, D. N. 2008. Raffaelea lauricola, a new ambrosia beetle symbiont and pathogen on the
Lauraceae. Mycotaxon 104:399-404.

15. Kinuura, H. 2002. Relative dominance of the mold fungus, Raffaelea sp., in the mycangium and proventriculus in relation to adult stages of the oak platypodid beetle, Platypus quercivorus (Coleoptera; Platypodidae). J. For. Res. 7:7-12.

16. Klepzig, K. D., Moser, J. C., Lombardero, M. J., Hofstetter, R. W., and Ayers, M. P. 2001. Symbiosis and competition: complex interactions among beetles, fungi and mites. Symbiosis 30:83-96.

17. Kubono, T, and Ito, S. 2002. Raffaelea quercivora sp. nov. associated with mass mortality of Japanese oak, and the ambrosia beetle (Platypus quercivorus). Mycoscience 43:255-260.

18. Mayfield, A. E., Smith, J. A., Hughes, M., and Dreaden, T. J. 2008. First report of laurel wilt disease caused by a Raffaelea sp. on avocado in Florida. Plant Dis. 92:976.

19. Rabaglia, R. J., Dole, S. A., and Cognato, A. I. 2006. Review of American Xyleborina (Coleoptera: Curculionidae: Scolytinae) occurring north of Mexico, with an illustrated key. Ann. Entomol. Soc. Am. 99:1034-1056.

20. Scott, D. B., and du Toit, J. W. 1970. Three new Raffaelea species. Trans. Br. Mycol. Soc. 55:181-186.

21. Scott, J. J., Oh, D. C., Yuceer, M. C., Klepzig, K. D., Clardy, J., and Currie, C. R. 2008. Bacterial protection of beetle-fungus mutualism. Science 322:63.

22. Six, D. L. 2003. Bark beetle-fungus symbioses. Pages 99-116 in: Insect Symbiosis. K. Bourtzis and T. A. Miller, eds. CRC Press, Boca Raton, FL.

23. Suh, S. O., McHugh, J. V., Pollock, D. D., and Blackwell, M. 2005. The beetle gut: a hyperdiverse source of novel yeasts. Mycol. Res. 109:261-265.

24. Webber, J. F., and Gibbs, J. N. 1989. Insect dissemination of fungal pathogens of trees. Pages 161-193 in: Insect-Fungus Interaction. N. Wilding, N. M. Collins, P. M. Hammond, and J. F. Webber, eds. Academic Press, London.

25. Wood, S. L., and Bright, D. E. 1992. A catalog of Scolytidae and Platypodidae (Coleoptera), Part 2: Taxonomic index, volumes A and B. Great Basin Nat. Mem. No. 13. 